\title{
Effect of Draw Ratio and Sheet Thickness on Earing and Drawability of Al 1200 Cups
}

\section{O.O. Oluwole ${ }^{1 *}$, C.O. Anyaeche ${ }^{2}$ and O.V. Faola ${ }^{3}$}

\author{
${ }^{1}$ Mechanical Engineering Department, University of Ibadan. \\ ${ }^{2}$ Production Engineering Department,Universitry of Ibadan. \\ ${ }^{3}$ Department of Metallurgical and Materials Engineering, \\ FUT, Akure, Nigeria.
}

\begin{abstract}
*Corresponding author: lekeoluwole@gmail.com +234(0)8033899701
\end{abstract}
\begin{abstract}
The effect of blank/punch diameter ratio (draw ratio) in deep drawing on earing for different gauges of Al 1200 sheet was studied. Using 60, 62, 64 and 65mm diameter circle blanks and $33 \mathrm{~mm}$ diameter punch die, fully annealed Al 1200 sheets of gauge thicknesses 0.6 to $2.0 \mathrm{~mm}$ were subjected to deep drawing on an Errichsen ${ }^{R}$ cup drawing machine.

The results showed that with increase in sheet thickness, the smaller is the draw ratio that would draw the sheet. For 0.6-0.9mm sheet thickness, cups were drawn with draw ratios of 60/33 to 65/33. For sheet thicknesses of 1.2-1.58mm, only 60/33 and 62/33 draw ratios were observe to draw cups. Earing was observed to generally increase with increasing draw ratio using the same sheet thickness. It was also observed that for thinner sheets (0.6-0.9mm), using the same draw ratio, earing increased with increasing sheet thickness. For thicker sheets (1.2-1.58mm) earing was observed to decrease with increasing sheet thickness. After that, there was an increase for deep-drawn $2 \mathrm{~mm}$ thick sheet.
\end{abstract}

Higher draw ratios were observed to draw deeper cup depths with minimal earing. The depth of cups drawn with 65/33 draw ratio was observed to be about 28\% more than those drawn with $60 / 33$ draw ratio with an increase in earing of only $0.84 \%$ for $0.6 \mathrm{~mm}$ thick sheet and $1.2 \%$ for $0.9 \mathrm{~mm}$ thick sheets. Earing was also observed to increase by $1.64 \%$ for the $2 \mathrm{~mm}$ thick sheet that had undergone grain growth over the fine grained one.

Key words: Earing; punch die/blank diameter ratio; deep drawing; Al 1200 


\section{INTRODUCTION}

Al 1200 is the grade of aluminium used for hollowware. When cold rolled, aluminium or its alloys are recrystallised by annealing. New grains form with orientations that differ from those present in the cold rolled condition[1]. Preferred orientation is much reduced but seldom eliminated. Preferred orientation in the plane of a sheet that is associated with textures may cause a problem known as earing. Earing is wasteful of material because larger blank than necessary must be used in deep drawing hollowware production. Moreover, it may lead to the production problems due to difficulties in ejecting products after a pressing operation.

Much work has been done in the area of earing and texture[2,3]. Four ears usually form because of non-uniform plastic deformation along the rim of deep drawn products if there is a desirable balance between the rolling texture and the annealing texture; however, eight small ears could be formed or none at all. Because of this possibility of annealing to produce a texture which could minimize or eliminate earing, the careful control of cold roll and planar anisotropy by annealing schedules is normal undertaken[2,4,5] .

The effect of draw ratio on earing of Al 1200 during deep-drawing was studied in this work using various sheet thicknesses.

\section{MATERIALS AND METHOD}

Starting materials were $\mathrm{Al} 1200$ as cast in the form of sheets of starting thicknesses of 8mm, 7.34mm and 6mm obtained from Aluminium Rolling Mills Ota, Ogun State, Nigeria. The average chemical composition is shown in Table 1.

Table 1: Average Chemical Composition (Wt \%) Of Aluminium 1200

\begin{tabular}{|l|l|l|l|l|}
\hline $\mathrm{Fe}$ & $\mathrm{Si}$ & $\mathrm{Mg}$ & $\mathrm{Mn}$ & $\mathrm{Al}$ \\
\hline 0.53 & 0.225 & 0.025 & 0.025 & Balance \\
\hline
\end{tabular}

The starting material was annealed at $460^{\circ}$ for 6 hours. The annealed sheets were cold-rolled to different thicknesses, 2, 1.58, 1.55, 1.51, 1.48, 1.17, 0.9, 0.84, 0.75 and 0.6mm. After cold -roll, annealing temperatures were selected as suited to each degree of cold roll [5] to achieve H0 hardness. A Heraus ${ }^{R}$ industrial Muffle furnace was used for annealing and cooling was done in air [4]. The annealed specimens were prepared for deep drawing by blanking them into 60, 62, 64, 65 and 70mm circle blank diameters. Using an Errichssen ${ }^{\mathrm{R}}$ deep-drawing machine, a 33mm diameter deep-drawing die was used in deep-drawing the prepared circle blanks into cups. Earing developed at the rims of the cups were measured using standard measuring techniques [2]. This 
research work was carried out in the quality control laboratory of Aluminium Rolling Mills, Ota,Ogun State, Nigeria.

\section{RESULTS AND DISCUSSION}

\subsection{Results}

The results obtained are presented in Tables 2- 8. Table 2 shows the drawability of varying thicknesses of $\mathrm{Al} 1200$ cups with varying punch/blank diameter ratio. The result showed that thicknesses of $1.17-1.58 \mathrm{~mm}$ can be drawn by only draw ratio of 62/33 and 60/33 while smaller gauges of $0.6-0.9 \mathrm{~mm}$ could be drawn by draw ratios of 60/33 - 65/33.

Table 2: Drawability of Varying Thicknesses of Al 1200 cups with varying punch/blank ratio

\begin{tabular}{|l|l|l|}
\hline $\begin{array}{l}\text { Sample } \\
\text { Thickness }(\mathrm{mm})\end{array}$ & Blank diameter $(\mathrm{mm})$ & $1^{\text {st }}$ Draw \\
\hline 2.0 & 60 & Drawn \\
\hline 1.58 & 60 & Drawn \\
\hline 1.58 & 62 & Drawn \\
\hline 1.58 & 64 & Broken \\
\hline 1.58 & 65 & Broken \\
\hline 1.58 & 70 & Broken \\
\hline 1.55 & 60 & Drawn \\
\hline 1.55 & 62 & Drawn \\
\hline 1.17 & 60 & Drawn \\
\hline 1.17 & 62 & Drawn \\
\hline 1.17 & 64 & Broken \\
\hline 1.17 & 65 & Broken \\
\hline 1.17 & 70 & Broken \\
\hline 0.9 & 60 & Drawn \\
\hline 0.9 & 65 & Drawn \\
\hline 0.75 & 60 & Drawn \\
\hline 0.75 & 62 & Drawn \\
\hline 0.75 & 64 & Drawn \\
\hline 0.75 & 65 & Drawn \\
\hline 0.75 & 70 & Broken \\
\hline 0.6 & 60 & Drawn \\
\hline 0.6 & 65 & Drawn \\
\hline & & \\
\hline & 65 & 65 \\
\hline
\end{tabular}

Table 3 shows variation of earing with varying draw ratio (plate thickness kept constant). The same result is presented in Fig.3. It was observed that increasing draw ratio increased earing. 
Table 3: Variation of Earing of Al 1200 cups with varying blank-diameter/ punch-die ratio (plate thickness kept constant).

\begin{tabular}{|l|l|l|}
\hline $\begin{array}{l}\text { Test piece } \\
\text { thickness(mm) }\end{array}$ & $\begin{array}{l}\text { Blank } \\
\text { Diameter(mm) }\end{array}$ & Earing \% \\
\hline 0.60 & 65 & 1.2 \\
\hline 0.60 & 60 & 0.39 \\
\hline 0.75 & 65 & 3.43 \\
\hline 0.75 & 64 & 3.24 \\
\hline 0.90 & 65 & 4.65 \\
\hline 0.90 & 64 & 2.85 \\
\hline 0.90 & 60 & 3.9 \\
\hline 1.55 & 62 & 2.23 \\
\hline 1.55 & 60 & 1.87 \\
\hline 2.0 & 60 & 4.84 \\
\hline
\end{tabular}

The results of variation of earing with varying plate thicknesses (draw ratio kept constant) are presented in Table 4 and Fig. 4. While earing was observed to increase with increasing sheet thickness for $0.6-0.9 \mathrm{~mm}$ thick sheets, the reverse was true for $1.2-1.55 \mathrm{~mm}$ sheets. At $2 \mathrm{~mm}$ thickness, earing was observed to shoot-up again.

Table 4: Variation of Earing of Al 1200 cups with varying plate thicknesses (Blankdiameter/punch-die ratio kept constant)

\begin{tabular}{|l|l|l|}
\hline $\begin{array}{l}\text { Test piece } \\
\text { thickness(mm) }\end{array}$ & $\begin{array}{l}\text { Blank } \\
\text { Diameter(mm) }\end{array}$ & Earing \% \\
\hline 0.60 & 65 & 1.2 \\
\hline 0.75 & 65 & 3.43 \\
\hline 0.84 & 65 & 3.98 \\
\hline 0.90 & 65 & 4.65 \\
\hline 0.75 & 64 & 3.24 \\
\hline 0.76 & 64 & 3.80 \\
\hline 0.90 & 64 & 2.85 \\
\hline 1.20 & 62 & 3.51 \\
\hline 1.51 & 62 & 2.68 \\
\hline 1.55 & 62 & 2.23 \\
\hline 0.60 & 60 & 0.39 \\
\hline 0.90 & 60 & 3.9 \\
\hline 1.20 & 60 & 3.38 \\
\hline 1.48 & 60 & 1.99 \\
\hline 1.55 & 60 & 1.87 \\
\hline 2.0 & 60 & 4.84 \\
\hline
\end{tabular}


Table 5 presents the variation of depth of drawn cup and earing with draw ratio for $0.6 \mathrm{~mm}$ sheets. The depth of cups drawn with 65/33 draw ratio was observed to be about $28 \%$ more than drawing with 60/33 draw ratio with an increase in earing of only $0.84 \%$.

Table 5: Variation of Depth of Drawn cup and Earing with Blank-Diameter/Punch-Die Ratio for Al 1200 cups using fully annealed $0.6 \mathrm{~mm}$ thick Sheet.

\begin{tabular}{|l|l|l|l|l|l|}
\hline $\begin{array}{l}\text { Anneal-Time } \\
(H r s) \text { at } 460^{\circ} C\end{array}$ & $\begin{array}{l}\text { Temper } \\
\text { Designation }\end{array}$ & $\begin{array}{l}\text { Draw Ratio } \\
\text { Blank } \Phi / \text { Punch } \Phi\end{array}$ & $1^{\text {st }}$ Draw & $2^{\text {nd }}$ Draw & Earing(\%) \\
\hline 1 & 0 & $60 / 33$ & 22.4 & 28.3 & 0.02 \\
\hline 2 & 0 & $60 / 33$ & 21.1 & 28.0 & 0.72 \\
\hline 3 & 0 & $60 / 33$ & 21.5 & 28.0 & 0.30 \\
\hline 4 & 0 & $60 / 33$ & 22.6 & 28.5 & 0.39 \\
\hline 1 & 0 & $65 / 33$ & 28.0 & 35.8 & 0.36 \\
\hline 2 & 0 & $65 / 33$ & 27.9 & 35.8 & 2.5 \\
\hline 3 & 0 & $65 / 33$ & 28.0 & 35.9 & 1.4 \\
\hline 4 & 0 & $65 / 33$ & 28.0 & 35.8 & 1.2 \\
\hline
\end{tabular}

The variation of depth of drawn cup and earing with draw ratio for $0.9 \mathrm{~mm}$ sheets is presented in Table 6. The depth of cups drawn with 65/33 draw ratio was observed to be about $28 \%$ more than drawing with 60/33 draw ratio with about $1.2 \%$ increase in earing.

Table 6: Variation of Depth of Drawn cup and Earing with Blank-Diameter/Punch-Die Ratio for Al 1200 cups using fully annealed $0.9 \mathrm{~mm}$ thick Sheet.

\begin{tabular}{|l|l|l|l|l|l|}
\hline $\begin{array}{l}\text { Anneal-Time } \\
(H r s) \text { at } 460^{\circ} \mathrm{C}\end{array}$ & $\begin{array}{l}\text { Temper } \\
\text { Designation }\end{array}$ & $\begin{array}{l}\text { Draw Ratio } \\
\text { Blank } \Phi / \text { Punch } \Phi\end{array}$ & $1^{\text {st }}$ Draw & $2^{\text {nd }}$ Draw & Earing(\%) \\
\hline 1 & 0 & $60 / 33$ & 23.0 & 28.9 & 3.5 \\
\hline 2 & 0 & $60 / 33$ & 22.8 & 29.0 & 3.9 \\
\hline 3 & 0 & $60 / 33$ & 23.0 & 28.8 & 3.9 \\
\hline 4 & 0 & $60 / 33$ & 23.0 & 28.8 & 3.9 \\
\hline 1 & 0 & $65 / 33$ & 27.8 & 36.4 & 9.3 \\
\hline 2 & 0 & $65 / 33$ & 27.9 & 36.3 & 5.4 \\
\hline 3 & 0 & $65 / 33$ & 28.0 & 36.5 & 3.9 \\
\hline 4 & 0 & $65 / 33$ & 27.8 & 36.6 & 6.1 \\
\hline
\end{tabular}

Table 7 presents the variation in depth of drawn cups and earing with annealing time for fully annealed $2 \mathrm{~mm}$ thick sheet while Table 8 presents values of earing and depth of drawn cups for over-annealed $2 \mathrm{~mm}$ sheets. The result showed that earing increased with grain growth from overannealing. 
Table 7: Variation of Depth of Drawn cup and Earing with increasing annealing Temperature using $2 \mathrm{~mm}$ thick Sheet.

\begin{tabular}{|l|l|l|l|l|l|}
\hline $\begin{array}{l}\text { Anneal-Time } \\
(\text { Hrs }) \text { at } 400^{\circ} C\end{array}$ & $\begin{array}{l}\text { Temper } \\
\text { Designation }\end{array}$ & $\begin{array}{l}\text { Draw Ratio } \\
\text { Blank } \Phi / \text { Punch } \Phi\end{array}$ & $1^{\text {st Draw }}$ & $2^{\text {nd }}$ Draw & Earing(\%) \\
\hline 1 & 0 & $60 / 33$ & 23.3 & 28.0 & 4.3 \\
\hline 2 & 0 & $60 / 33$ & 23.3 & 28.0 & 4.3 \\
\hline 3 & 0 & $60 / 33$ & 23.2 & 28.2 & 2.6 \\
\hline 4 & 0 & $60 / 33$ & 23.0 & 28.8 & 3.4 \\
\hline
\end{tabular}

Table 8: Variation of Depth of Drawn cup and Earing with increasing Annealing Time using 2mm thick Sheet.

\begin{tabular}{|l|l|l|l|l|l|}
\hline $\begin{array}{l}\text { Anneal-Time } \\
(\text { Hrs }) \text { at } 460^{\circ} C\end{array}$ & $\begin{array}{l}\text { Temper } \\
\text { Designation }\end{array}$ & $\begin{array}{l}\text { Draw Ratio } \\
\text { Blank } \Phi / \text { Punch } \Phi\end{array}$ & $1^{\text {st Draw }}$ & $2^{\text {nd }}$ Draw & Earing(\%) \\
\hline 1 & 0 & $60 / 33$ & 22.4 & 28.2 & 4.1 \\
\hline 2 & 0 & $60 / 33$ & 22.3 & 28.0 & 7.5 \\
\hline 3 & 0 & $60 / 33$ & 22.5 & 28.4 & 5.1 \\
\hline 4 & 0 & $60 / 33$ & 22.4 & 28.1 & 4.2 \\
\hline
\end{tabular}

Fig.1 shows broken cups drawn with 64/33, 65/33 and 70/33 draw ratios. Fig.2 shows earing in some deep-drawn samples.

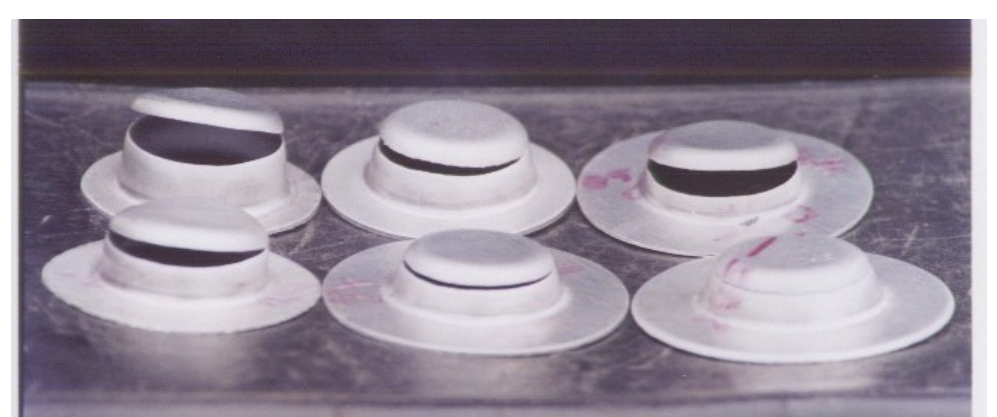

Fig. 1: Broken cups using 64, 65 and 70/33mm draw ratios

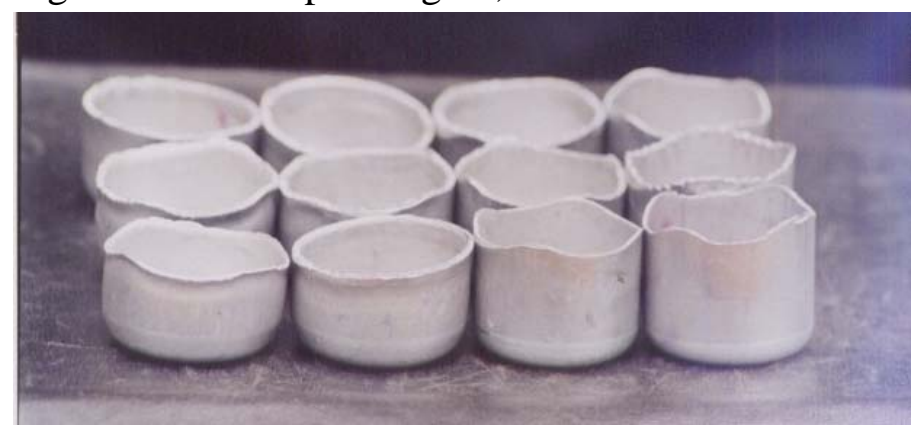

Fig. 2: Four sets of cups of varying thicknesses showing ears formed at the rims. 


\subsection{Discussions}

\subsubsection{Drawability of different sheet thickness}

For the sheet thicknesses tested (Table 2), it was observed that sheets of thicknesses within the range $0.6-0.9 \mathrm{~mm}$ were drawn by draw ratios $60 / 33$ to $65 / 33$.

For thicker sheets of $1.2-1.58 \mathrm{~mm}$, only $60 / 33$ and $62 / 33$ draw ratios were observe to draw cups. Cups drawn with higher draw ratios were observed to break (Fig.1).

\subsubsection{Earing variation with draw ratio and sheet thickness}

Fig.3 shows the variation of earing with increasing draw ratio for different sheet thickness. Earing was observed to generally increase with increasing draw ratio using the same sheet thickness. The increase in earing with increase in draw ratio can be attributed to increased material available for draw.

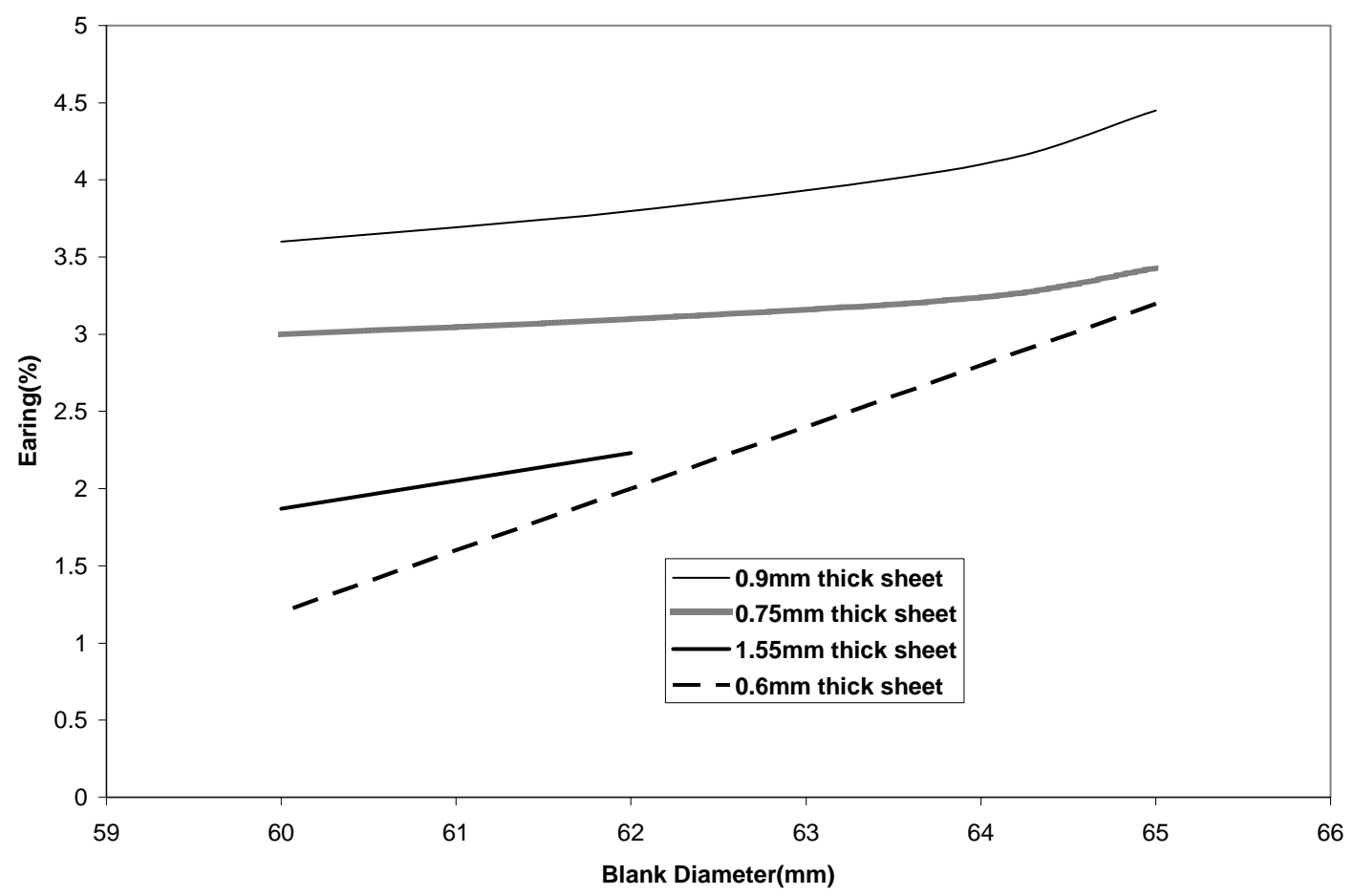

Fig. 3: Variation Trend of Earing with increasing Draw Ratio (Sheet Thickness kept constant)

It was observed that for thinner sheets $(0.6-0.9 \mathrm{~mm})$, using the same draw ratio, earing increased with increasing sheet thickness (Fig.4). For thicker sheets (1.2-1.58mm) earing was observed to decrease with increasing sheet thickness; after which there was an increase for deep-drawn $2 \mathrm{~mm}$ 
thick sheet. This behaviour can be explained by the texture (preferred orientation) of the material. Earing has been observed to increase generally with increasing planar anisotropy [2].

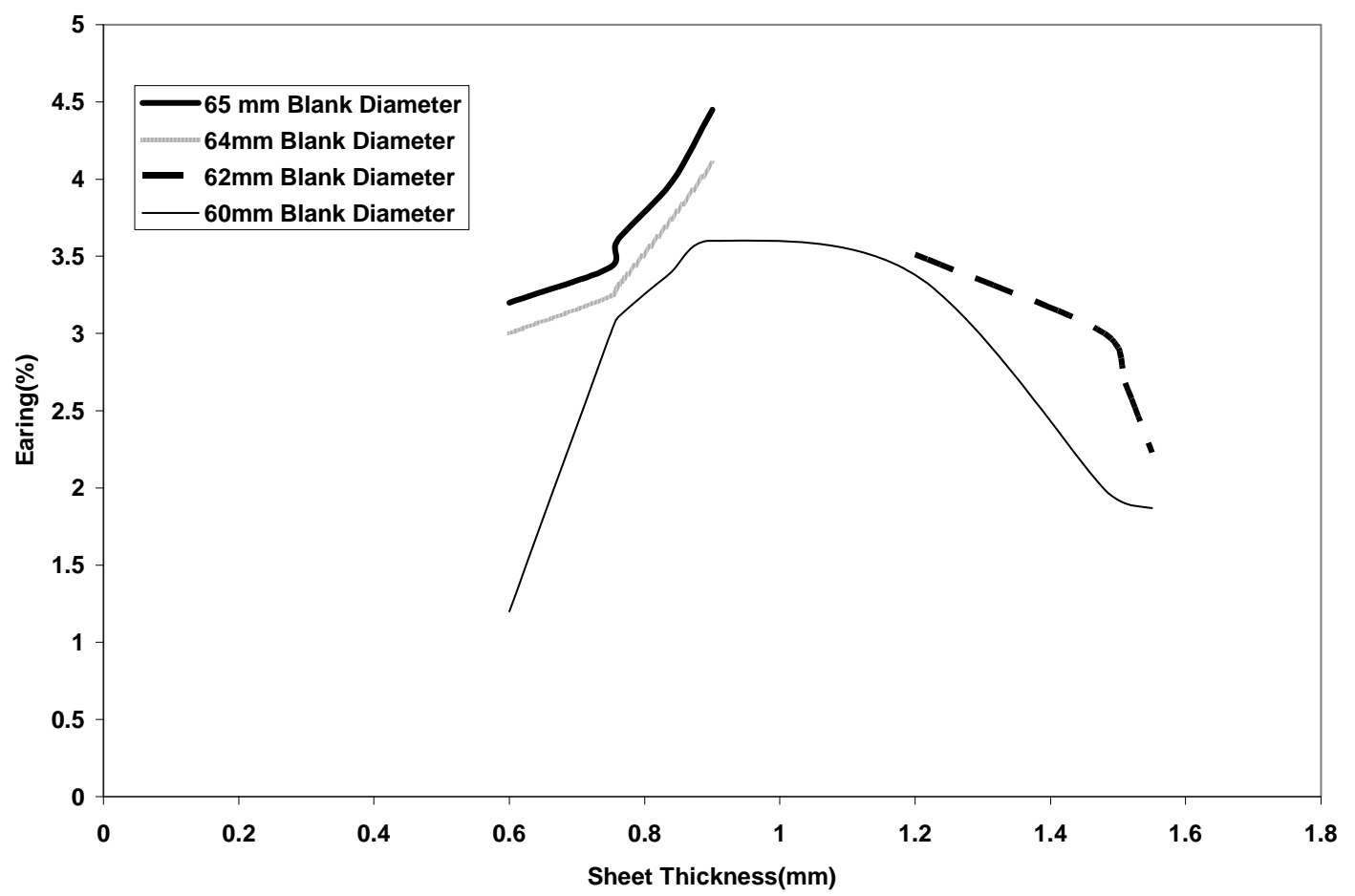

Fig. 4: Variation Trend of Earing with increasing Sheet Thickness (Draw Ratio kept constant).

\subsubsection{Drawn-Cup depth and earing variation with draw ratio and thickness.}

At 60/33 draw ratio, drawn cup depth was observed to increase with increasing sheet thickness at first draw for all thicknesses and at second draw for 0.6 and $0.9 \mathrm{~mm}$ thick sheets (Tables 5-7). There was not much gain in depth for deep-drawn $2 \mathrm{~mm}$ thick sheets at second draw over the $0.6 \mathrm{~mm}$ thick sheet.

Earing was observed to increase with increasing sheet thickness, however, from $0.36 \%$ in deepdrawn $0.6 \mathrm{~mm}$ sheets to $3.9 \%$ in deep-drawn $0.9 \mathrm{~mm}$ sheets and remaining about steady at $3.6 \%$ for deep-drawn $2 \mathrm{~mm}$ thick sheet.

At 65/33 draw ratio, drawn-cup depth was observed to increase with increasing sheet thickness at second draw only for 0.6 and $0.9 \mathrm{~mm}$ thick sheets. Earing was observed to increase as well with increasing sheet thickness, from $1.7 \%$ in deep-drawn $0.6 \mathrm{~mm}$ sheets to $5.1 \%$ in deep-drawn $0.9 \mathrm{~mm}$ sheets. 
The increase in drawn-cup depth with increasing thickness could be attributed to increased area available for draw. The increase in earing is attributable to the texture of the material causing ears (Fig.2).

65/33 draw ratio was observed to draw deeper cup depths compared with cups drawn with 60/33 draw ratio. This was expected because of the larger blank size available for draw. The depth of cups drawn with 65/33 draw ratio was observed to be about $28 \%$ more than those drawn with $60 / 33$ draw ratio with an increase in earing of only $0.84 \%$ for $0.6 \mathrm{~mm}$ thick sheet and $1.2 \%$ for $0.9 \mathrm{~mm}$ thick sheets.

\subsubsection{Drawn-Cup depth and earing variation grain growth}

Table 8 shows the results obtained from drawing with 2mm thick Al 1200 sheet that has undergone grain growth. The results showed smaller cup depth at first draw compared to cup drawn from fine grained $2 \mathrm{~mm}$ thick sheet (Table 7). At second draw, cup depth was the same depth as cups draw from the fine grained material. However, earing was observed to increase by $1.64 \%$ for the large grained material. The effect of grain growth causing the material to be less ductile can be attributed to increased earing.

\section{CONCLUSION}

The following conclusions were drawn from this work:

The results showed that with increase in sheet thickness, the smaller is the draw ratio to draw the sheet. For 0.6-0.9mm sheet thickness, cups were drawn with draw ratios of 60/33 to 65/33. For sheet thicknesses of $1.2-1.58 \mathrm{~mm}$, only $60 / 33$ and 62/33 draw ratios were observe to draw cups.

Earing was observed to generally increase with increasing draw ratio using the same sheet thickness.

It was also observed that for thinner sheets $(0.6-0.9 \mathrm{~mm})$, using the same draw ratio, earing increased with increasing sheet thickness. For thicker sheets $(1.2-1.58 \mathrm{~mm})$ earing was observed to decrease with increasing sheet thickness after which earing increased for $2 \mathrm{~mm}$ thick sheet

Higher draw ratios were observed to draw deeper cup depths with minimal earing. The depth of cups drawn with 65/33 draw ratio was observed to be about $28 \%$ more than those drawn with $60 / 33$ draw ratio with an increase in earing of only $0.84 \%$ for $0.6 \mathrm{~mm}$ thick sheet and $1.2 \%$ for $0.9 \mathrm{~mm}$ thick sheets. Earing was also observed to increase by $1.64 \%$ for the $2 \mathrm{~mm}$ thick sheet that had undergone grain growth over the fine grained one. 


\section{REFERENCES}

[1] Polmear I. J., (1981): Light alloys, metallurgy of he light metals, Advanced Arnold Publishers, London $2^{\text {nd }}$ Edition, Pp 76-79, $104-105$.

[2] Oluwole O.O, Ajayi.J.A, Olorunniwo.O.E and Sofoluwo.A.A(2002) 'Texture and Structure of Cold-Rolled and Temper-Annealed Al 1200’ NSE Technical Transactions 37(2);53-69.

[3] Aderibigbe. D.A , Oluwole.O.O, Olorunniwo.O.E, Atanda, P.O and Ogundare.O(2006) 'Earing Characteristics of Cold-Rolled and Temper -Annealed Al 1200' Journal of Applied Sciences, INSINET, 6(15),3103-3109

[4] Baker A.M. (1977): Comparison of Mechanical properties for temper-rolled and temperannealed strips of Aluminium 1100, CES Aluminium and Brass, America Society of metals, U.S.A. Vol III, 1 - 12.

[5] Aderibigbe. D.A and Sowole.O(1989) 'Effects of Temper Annealing Temperatures and Times on the Mechanical Properties of Cold-Worked Al 1200’ Journal of Engineering Reserch JER-1(1); 49-59. 